ISSN electrónico: 2445-1355

DOI: https://dx.doi.org/10.14201/fj2020524350

\title{
BÚSQUEDA DE BACTERIAS PRODUCTORAS DE ANTIBIÓTICOS A PARTIR DEL CULTUROMA RIZOSFÉRICO
}

\section{Bio-Prospecting for Antibiotic Producing Bacteria from the Rhizospheric Culturome}

Noelia FERNÁNDEZ-VILLACORTA; Pedro F. MATEOS; Zaki SAATI-SANTAMARÍA*

Departamento de Microbiología y Genética. Facultad de Farmacia. Dirección: Edificio Departamental, laboratorio 213. Campus Miguel de Unamuno. 37007 Salamanca

Correo-e: *zakisaati@usal.es

RESUMEN: El consumo indebido de antibióticos ha incrementado el número de personas que enferman y mueren por infecciones provocadas por microorganismos resistentes a estos antimicrobianos. El objetivo de este estudio fue aislar bacterias rizosféricas y evaluar su potencial para producir nuevos compuestos antimicrobianos. Se aislaron 418 colonias y se enfrentaron a bacterias y hongos para analizar su potencial antimicrobiano, encontrando 114 bacterias productoras de antibiótico. Se seleccionaron dos de las cepas con mejor espectro antimicrobiano de acción, que se identificaron como Bacillus albus y Streptomyces cirratus. Se secuenciaron sus genomas y se analizaron las rutas relacionadas con el metabolismo secundario bacteriano, encontrando maquinaria genética que podría estar implicada en la producción de nuevos compuestos bioactivos.

Palabras clave: antibióticos; metabolitos secundarios; genomas; antiSMASH.

ABSTRACT: The inappropriate use of antibiotics has increased the number illnesses and deaths because of multidrug resistant microbial 
caused infections. The objective of this study was to isolate rhizospheric bacteria and evaluate their potential to produce antimicrobial compounds. 418 bacterial colonies were isolated and assayed against bacteria and fungi in order to analyze their antimicrobial potential, finding 114 antimicrobial producing strains. Two of these strains with best antimicrobial spectrum of action were selected for further analyses, and were identified as Bacillus albus and Streptomycs cirratus. Their genomes were sequenced and secondary metabolism pathways were analyzed, finding genetic machinery potentially implicated in the production of new bioactive compounds.

Keywords: antibiotics; secondary metabolites; genomes; antiSMASH.

\section{INTRODUCCIÓN}

España encabeza la lista de países de Europa que hacen un uso inadecuado de antibióticos y de los que tienen un mayor impacto de infecciones entre la población. Los antibióticos han salvado muchas vidas a lo largo de los últimos 80 años, pero en las últimas décadas se ha intensificado el consumo desmesurado y el uso irresponsable de antibióticos de uso clínico, que, junto con la capacidad de mutación de los microorganismos, ha incrementado el número de bacterias y hongos multirresistentes (Horcaja et al., 2018).

Esto ha derivado en un aumento de la morbilidad y la mortalidad de los pacientes y el consiguiente aumento de los costes sanitarios. Por ello se está acelerando la implementación de políticas de control de antibióticos e investigando distintos enfoques para descubrir y desarrollar nuevos antibióticos y estrategias antimicrobianas (Banin et al., 2017).

El desarrollo de las tecnologías de secuenciación masiva durante los últimos años ha dado lugar a un auge sin precedentes en el área de la genómica, dando lugar a múltiples estudios donde se aplican herramientas bioinformáticas para descifrar el potencial genético de los microorganismos, lo cual también puede ser empleado en la búsqueda de nuevas sustancias bioactivas (Jiménez-Gómez et al., 2019).

La rizosfera, debido a su gran contenido en nutrientes, supone un entorno que favorece el crecimiento de una gran variedad de organismos. Consecuentemente, existe una gran competencia por conseguir estos nutrientes. Algunas bacterias rizosféricas son capaces de producir mayor cantidad de metabolitos secundarios que, aunque no son esenciales para el crecimiento, tienen un papel fisiológico asociado a favorecer la supervivencia y la competitividad bacteriana en un nicho determinado (Matilla, Krell, 2017). 
Debido a lo anteriormente expuesto, la rizosfera supone un nicho con potencial para encontrar bacterias productoras de nuevos metabolitos secundarios con utilidad en la industria farmacéutica. Así pues, en el presente trabajo, aislamos bacterias de rizosfera y, tras seleccionar e identificar aquellas con mayor capacidad para inhibir a otros microorganismos, secuenciamos sus genomas y analizamos las rutas metabólicas relacionadas con el metabolismo secundario bacteriano.

\section{Materiales y mÉtodos}

\subsection{Aislamiento y selección de bacterias productoras de antibióticos}

Se recolectaron muestras de suelo rizosférico. Se realizaron diluciones seriadas de suelo en agua estéril y se sembraron en placas Petri con los medios de cultivo Agar Nutritivo (AN) $\left(\right.$ Sigma $\left.^{\circledR}\right)$ y M65 (4 g glucosa, 4 g extracto de levadura, 10 g extracto de malta, $2 \mathrm{~g} \mathrm{CaCO}_{3}, 12 \mathrm{~g}$ agar y $1000 \mathrm{ml}$ agua destilada), incubadas a $28^{\circ} \mathrm{C}$ durante 7 días.

Se resembraron las colonias que presentaban una morfología diferente sobre placas de AN conteniendo esporas de Bacillus subtilis, inoculadas por vertido en placa. Aquellas bacterias que fueron capaces de inhibir el crecimiento de $B$. subtilis se resembraron en nuevas placas por agotamiento en estría hasta obtener cultivos puros. Las cepas seleccionadas se preservaron en tubos criogénicos con glicerol al $25 \%$ a $-80^{\circ} \mathrm{C}$ para su posterior uso.

\subsection{Espectro de actividad}

Cada cepa bacteriana se sembró en placas de Mueller-Hinton (Scharlau $\left.{ }^{\circledR}\right)$, incubadas a $28^{\circ} \mathrm{C}$. Tras 5 días de crecimiento, se realizó un ensayo de antagonismo según lo descrito en Saati-Santamaría et al. (2018) frente a bacterias Gram negativas (Serratia marcescens, Pseudomonas bohemica, Escherichia coli y Klebsiella oxytoca) y bacterias Gram positivas (Arthrobacter phenantrenivorans, Staphylococcus saprophyticus y Bacillus subtilis).

Se seleccionaron aquellas cepas que mostraron un amplio perfil de actividad antimicrobiana con las que se realizó un ensayo de inhibición frente a hongos filamentosos (Fusarium sp. y Aspergillus sp.) y hongos levaduriformes (Candida humilis y Saccharomyces cerevisae), incubados a $25^{\circ} \mathrm{C}$ durante 9 días.

En ambos casos se consideró como resultado positivo la aparición de un halo de inhibición alrededor de la bacteria de ensayo. 


\subsection{Asignación taxonómica, secuenciación y anotación de genomas}

Se extrajo el ADN total bacteriano de las dos cepas seleccionadas con el kit de extracción «Quick-DNA ${ }^{\mathrm{TM}}$ Fungal/Bacterial Miniprep», siguiendo las instrucciones del fabricante.

Se amplificó el gen 16S ARNr mediante PCR y se visualizó tras una electroforesis en gel de agarosa $(1 \mathrm{~g} / 100 \mathrm{~mL})$ (Poveda et al., 2019). Las bandas correspondientes al gen amplificado se cortaron del gel y se purificaron con el kit GeneJET Gel Extraction-ThermoFisher ${ }^{\mathrm{TM}}$, siguiendo las pautas descritas por el fabricante.

A continuación se secuenció el ADN en el Servicio de Secuenciación de ADN de la Universidad de Salamanca. Las secuencias de nucleótidos adquiridas se analizaron y procesaron con el programa MEGA $6.0^{\circledR}$, se ensambló cada secuencia utilizando el programa informático SeqMan ${ }^{\circledR}$. Se compararon las secuencias con las secuencias de cepas tipo utilizando las herramientas BLAST y EzBioCloud.

Se obtuvo un borrador de los genomas mediante la plataforma de secuenciación masiva Illumina Mi-Seq. Las secuencias genómicas fueron anotadas a través de la herramienta RAST 2.0. Para la búsqueda y predicción de los grupos de genes (clusters) involucrados en la producción de metabolitos secundarios se utilizó el programa antiSMASH 5.0.

\section{Resultados y discusión}

\subsection{Aislamiento y selección de bacterias productoras de antibióticos}

Se aislaron 418 colonias, de las cuales se seleccionaron 114 por su capacidad para inhibir a B. subtilis. Posteriormente, estas 114 seleccionadas se enfrentaron a bacterias Gram positivas y Gram negativas. S. marcescens fue fuertemente inhibida por 24 cepas (21,05\%), 8 la inhibieron de forma débil $(7,02 \%)$ y 82 no inhibieron el crecimiento de $S$. marcescens $(71,93 \%) .34$ cepas $(29,82 \%)$ inhibieron fuertemente el crecimiento de $K$. oxytoca, 5 de forma débil $(4,38 \%)$ y 75 cepas no la inhibieron $(65,80 \%) .39$ cepas $(34,21 \%)$ inhibieron fuertemente a $A$. phenanthrenivorans, 23 de forma débil $(20,18 \%)$ y 52 no fueron capaces de inhibirla (45,61 $\%$ ). S. saprophyticus fue inhibida fuertemente por 3 cepas $(2,63 \%), 20$ lo hicieron de forma débil $(17,54 \%)$ y 91 cepas no la inhibieron $(79,83 \%)$. El crecimiento de $B$. subtilis fue inhibido fuertemente por 48 cepas (42,11\%), 17 de forma débil $(14,91 \%)$ y 49 no lo inhibieron $(42,98 \%)$. E. coli fue inhibido fuertemente por 7 cepas $(6,14 \%), 10$ de forma débil (8,77\%), 97 no la inhibieron (85,09\%). 54 cepas $(47,37 \%)$ inhibieron fuertemente el crecimiento de $P$. bobemica, 4 de forma débil $(3,51 \%)$ y 56 no la inhibieron (49,12\%).

La cepa RMS 2-18 se seleccionó por su capacidad para inhibir a $P$. bohemica, $K$. oxytoca, $A$. phenanthrenivorans y $B$. subtilis y la cepa RMS 3-43 se seleccionó 
por inhibir a $P$. bobemica, A. phenanthrenivorans y $B$. subtilis en el ensayo de antagonismo frente a bacterias Gram negativas y Gram positivas (Fig. 1). Se realizó con estas dos cepas un ensayo de antagonismo frente a hongos filamentosos y hongos levaduriformes.

Las cepas bacterianas fueron capaces de inhibir a todos los hongos ensayados a excepción de Fusarium sp.

En la Figura 1 se observa como Fusarium sp. crece en presencia de RMS 3-43. En cambio, se visualiza como crece en menor cantidad en presencia de RMS 2-18.

FIgura 1. (A) Espectro de actividad de RMS 2-18, (B) RMS 2-18 con Aspergillus sp., (C) RMS 2-18 con C. humilis y S. cerevisiae, (D) RMS 2-18 con Fusarium sp.,

(E) Espectro de actividad de RMS 3-43, (F) RMS 3-43 con Aspergillus sp.,

(G) RMS 3-43 con C. bumilis y S. cerevisiae, (H) RMS 3-43 con Fusarium sp., 1: S. marcescens, 2: P. bobemica, 3: K. oxytoca, 4: A. phenanthrenivorans, 5: $S$. saprophyticus, 6: B. subtilis.

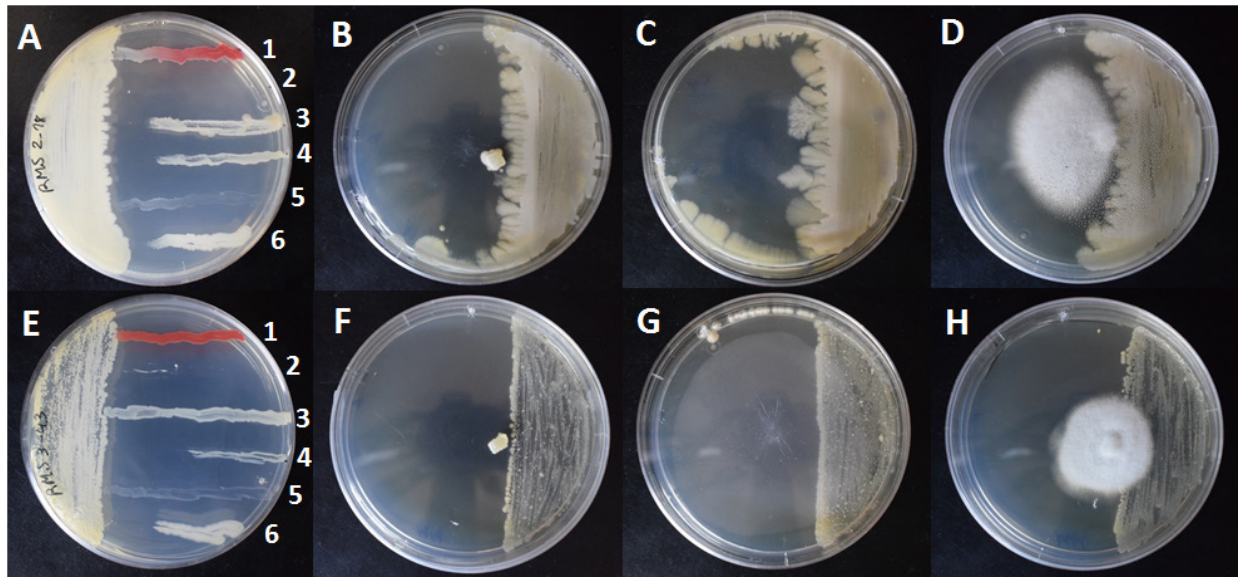

\subsection{Asignación taxonómica}

Las secuencias del gen 16S ARNr de las cepas RMS 2-18 y RMS 3-43 tuvieron un $100 \%$ de similitud con las de las cepas Bacillus albus N35-10-2 ${ }^{\mathrm{T}}$ y Streptomyces cirratus NRRL B-3250' , respectivamente.

Debido a la capacidad de las cepas RMS 2-18 y RMS 3-43 para inhibir a los microorganismos enfrentados y por pertenecer a géneros bacterianos productores de gran cantidad de metabolitos secundarios (Sansinenea y Ortiz, 2011; Demain, 1999), fueron escogidas para secuenciar su genoma y así predecir las posibles rutas biosintéticas de metabolitos secundarios con propiedades bioactivas. 


\subsection{Análisis de la secuenciación de los genomas}

En la Tabla 1 y en la Figura 2 se muestra la información recogida mediante la anotación de los genomas de ambas cepas en el programa RAST.

TABLA 1. Características genómicas de RMS 2-18 y RMS 3-43

\begin{tabular}{|c|c|c|}
\hline & RMS 2-18 & RMS 3-43 \\
\hline Tamaño del genoma $(\mathrm{pb})$ & $6,189,037$ & $\mathbf{7 , 9 1 0 , 1 2 1}$ \\
\hline Contenido de GC ( \%) & 34.8 & $\mathbf{7 2 . 2}$ \\
\hline N50 & 165811 & 17946 \\
\hline L50 & 10 & 124 \\
\hline Número de contigs & 135 & 819 \\
\hline Número de subsistemas & 359 & 350 \\
\hline Número de secuencias de codificación & 6469 & 7757 \\
\hline Número de ARNs & 115 & 78 \\
\hline
\end{tabular}

Figura 2. A: Propiedades genómicas de RMS 2-18; B: Propiedades genómicas de RMS 3-43

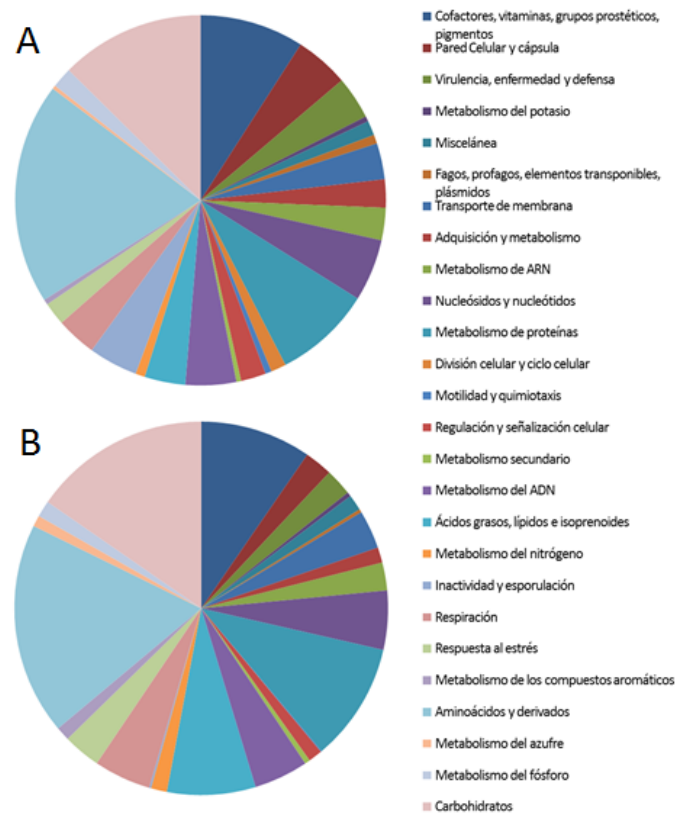

Ediciones Universidad de Salamanca / @@ఠ $\quad$ FarmaJournal, vol. 5, núm. 2 (2020), pp. 43-50 
Las anotaciones de antiSMASH para el genoma de la cepa RMS 3-43 nos revelaron 42 grupos de genes que podrían codificar rutas biosintéticas de nuevos metabolitos secundarios bioactivos, entre los que destacan 7 péptidos no ribosómicos (NRPS), 7 policétidos sintasas (PKS), 2 lantipéptidos y 2 bacteriocinas, debido a que las moléculas que sintetizan estas rutas suelen tener actividad antibiótica (Adamek et al., 2017). En el caso de la cepa RMS 2-18 encontramos 14 clusters, destacando 4 NRPS y 2 bacteriocinas.

La mayoría de los clusters no mostraban relación con otros clusters ya descritos para los cuales se conozcan las moléculas que biosintetizan. Esto podría suponer que estas agrupaciones de genes codificasen para sustancias aún no descritas y que podrían ser de interés como potenciales antimicrobianos. No obstante, sí que se encuentran clusters que están relacionados con algunos ya estudiados.

Para la cepa RMS 3-43 se predicen 8 clusters que parecen estar relacionados con otros descritos implicados en la síntesis de alguna sustancia conocida, como son la pentostatina, el hopeno, el lactazol, la geosmina, el isorenierateno, la sap $\mathrm{B}$, la desferoxamina $\mathrm{B}$ y la kirromicina, esta última relacionada con actividad antimicrobiana (Iftime et al., 2015).

Para la cepa RMS 2-18 antiSMASH predice 7 clusters que tienen similitud con otros ya descritos que producen alguna sustancia conocida, como son la pectrobactina, la polyoxipectina $\mathrm{A}$, el cofactor de molibdeno, la fengicina, bacilibactina y dos sustancias relacionadas con actividad antimicrobiana, la thurincina $\mathrm{H}$ (Wang et al., 2014) y la zwitermicina A (Kevany et al., 2009).

\section{Conclusiones}

El suelo rizosférico analizado contiene una gran proporción de bacterias productoras de sustancias con actividad antimicrobiana, por lo que podría llegar a ser una nueva fuente de compuestos de interés farmacéutico. Esto refleja que la investigación microbiológica de ecosistemas inexplorados es crucial para descubrir bacterias capaces de producir nuevos antibióticos, dada la necesidad por el auge de las resistencias a múltiples antimicrobianos.

Las cepas $B$. albus RMS 2-18 y $S$. cirratus RMS 3-43 muestran un gran interés como productoras de antibióticos y, puesto que hay una fracción sustancial de clusters biosintéticos relacionados con el metabolismo secundario que no guardan similitud con otros descritos, podrían derivar en futuras líneas de investigación para determinar si alguno de estos compuestos podría servir como un potencial antimicrobiano o para otro uso terapéutico.

En este trabajo se describe un protocolo novedoso y útil para la búsqueda, selección e identificación de posibles sustancias bioactivas producidas por bacterias. Este método combina los métodos clásicos microbiológicos con la genómica y 
bioinformática. Los resultados obtenidos avalan su potencial en la búsqueda de nuevas sustancias bioactivas.

\section{Agradecimientos}

Genome sequencing was provided by MicrobesNG (http://www.microbesng. uk), which is supported by the BBSRC (grant number BB/L024209/1).

\section{Bibliografía}

Adamek M, Spohn M, Stegmann E, Ziemert N. Mining bacterial genomes for secondary metabolite gene clusters. Methods Mol Biol. 2017; 1520:23-47.

Banin E, Hughes D, Kuipers O.P. Editorial: Bacterial pathogens, antibiotics and antibiotic resistance. FEMS Microbiol Rev. 2017; 41(3):450-452.

Demain A.L. Pharmaceutically active secondary metabolites of microorganisms. Appl Microbiol Biotechnol. 1999; 52(4):455-463.

Horcajada JP, Graus S, Paño-Pardo JR, López A, Oliver A, Cisneros JM et al. Antimicrobial stewardship in Spain: programs for optimizing the use of antibiotics (PROA) in Spanish hospitals. Germs. 2018; 8(3):109-112.

Iftime D, Kulik A, Härtner T, Rohrer S, Niedermeyer TH, Stegman E et al. Identification and activation of novel biosynthetic gene clusters by genome mining in the kirromycin producer Streptomyces collinus Tü 365. J Ind Microbiol Biotechnol. 2015; 4(2):277-291.

Jiménez-Gómez A, Saati-Santamaría Z, Igual JM, Rivas R, Mateos PF, García-Fraile P. Genome insights into the novel species Microvirga brassicacearum, a rapeseed endophyte with biotechnological potential. Microorganisms. 2019; 7(9):354.

Kevany BM, Raski DA, Thomas MG. Genetics of zwittermicin a production by Bacillus cereus. Appl Environ Microbiol. 2009; 75(4):1144-1155.

Matilla MA, Krell T. Bacterias rizosféricas como fuente de antibióticos. Alianzas y Tendencias. 2017; 2(1):14-21.

Poveda J, Jiménez-Gómez A, Saati-Santamaría Z, Usategui-Martín R, Rivas R, García-Fraile P. Mealworm frass as a potential biofertilizer and abiotic stress tolerance-inductor in plants. Appl Soil Ecol. 2019; 142:110-122.

Saati-Santamaría Z, López-Mondéjar R, Jiménez-Gómez A, Díez-Mendez A, Větrovský T, Igual JM et al. Discovery of phloeophagus beetles as a source of Psendomonas strains that produce potentially new bioactive substances and description of Peudomonas bohemica sp. nov. Front Microbiol. 2018; 9:913.

Sansinenea E, Ortiz A. Secondary metabolites of soil Bacillus spp. Biotechnol Lett. 2011, 33:1523-1538.

Wang G, Manns DC, Churey JJ, Worobo RW. Development of a homologous expression system for and systematic site-directed mutagenesis analysis of thurincin $\mathrm{H}$, a bacteriocin produced by Bacillus thuringiensis SF361. Appl Environ Microbiol. 2014; 80(12):3576-3584. 